\title{
Epidemiological studies concerning choice of population for immunoprophylaxis of influenza
}

\author{
I. T. I. NICULESCU \\ M.D. \\ L. Cretescu \\ M.D. \\ E. OpRESCU \\ M.D.
}

\author{
E. ZILISTEANU \\ M.D.
}

R. Crainic

M.D.

M. MATEPIUC
M.D.

WHO National Influenza Centre, Cantacuzino Institute, Bucharest, Rumania

\begin{abstract}
Summary
Epidemiological studies in naturally infected persons have shown that there is a significant relation between antibody levels to the current circulating virus and morbidity. Serological findings and morbidity data suggest: (1) that the serological survey is a more sensitive indicator for influenza outbreaks than is the clinical diagnosis and (2) that the 5-14 age group is first affected when an epidemic of influenza starts off. Consequently, school children may be the major source of influenza into family units and, therefore, among older segments of the population.

Exploring the relationships between influenza morbidity and natality, as well as influenza morbidity and mortality under 1 year of age, values of $<0.001$ (Student's $t$-test) were obtained. The linear regression analysis showed that both relationships were represented as straight lines.

From the results it seems logical to utilize the available vaccine for the protection of infants, school children and pregnant women. The vaccine-induced protection can offer significant, although not total, protection of the whole population and prevent obstetrical accidents.
\end{abstract}

COMPLETE annual coverage of the entire population by vaccination against influenza is undoubtedly unrealistic (Cockburn, 1973; Davenport, 1973; Marcus, Liem and André, 1974). Therefore the uses suggested for influenza virus vaccines are predicated by the objectives. The excess of general mortality speaks for itself (Langmuir and Housworth, 1969). To prevent deaths, in the majority of the countries, about 20 $25 \%$ of the population must be vaccinated for coverage of high-risk groups (Davenport, 1973). Even if the goal of annual vaccination of the highrisk group is attained, it is unlikely that the spread of an epidemic will be significantly influenced.
The effect of influenza virus infection on the outcome of a pregnancy (Coffey and Jessop, 1959, 1963; Barret-Connor, 1969) and the excess of neonatal and under one year of age mortality is increasingly recognized (Wynne-Griffith et al., 1972). Data on industrial losses, and the costs of epidemic influenza have been estimated and are now becoming available (Davenport, 1973). The public is becoming more aware of the ravages of influenza, and the demand that something be done is increasingly heard. These observations require that appropriate priorities should be established at the national level.

Epidemiological studies in naturally infected persons have shown that there is a significant relationship between circulating antibody levels (geometric means) to the current virus and morbidity, although now and then some individual exception may be noted. This is strongly supported by the correlation between monthly clinical influenza incidence and the serological survey of the population (Fig. 1), the latter being a more sensitive indicator of influenza outbreaks.

The age distribution of epidemic influenza is consistently expressed by the comparative morbidity in different age groups (Fig. 2). The major prevalence of clinical disease is more common in the age group 1 month to 14 years and especially in the age group of 5-14 years. After 15 years of age, there is usually a distinct progressive decrease in incidence.

These data are in agreement with classical data (Davenport, 1973) and with the serological survey (Fig. 3), the geometric mean titres in the 5-14 age group being commonly greater than in other groups. Moreover our serological findings support those of Jordan (1960) and of Mulder and Masurel (1958) that this group is first affected when an epidemic of influenza starts off (the statistical significant increase of the geometric mean titres in persons of more than 


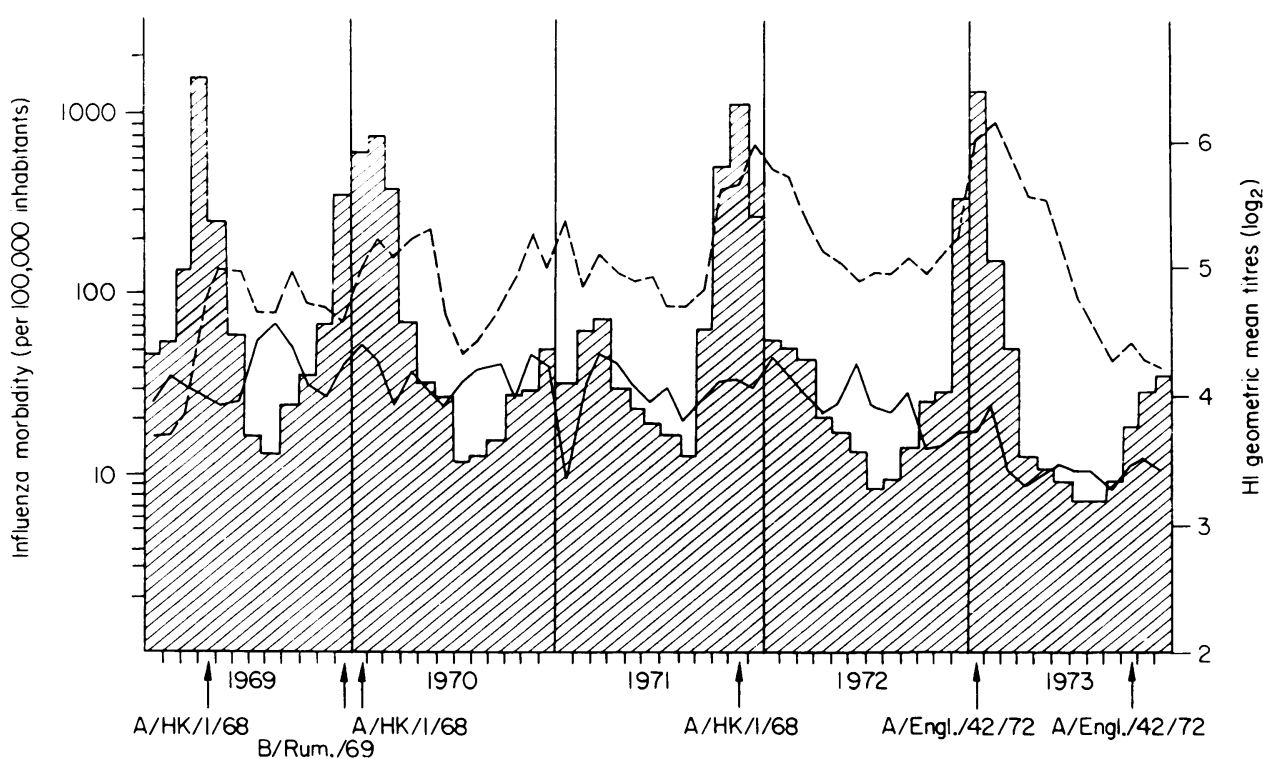

FIG. 1. Influenza morbidity $\mathbb{Z}$ and serological survey. HI geometric mean titres; - - -, A/HK/68; B/Rum/ 69.

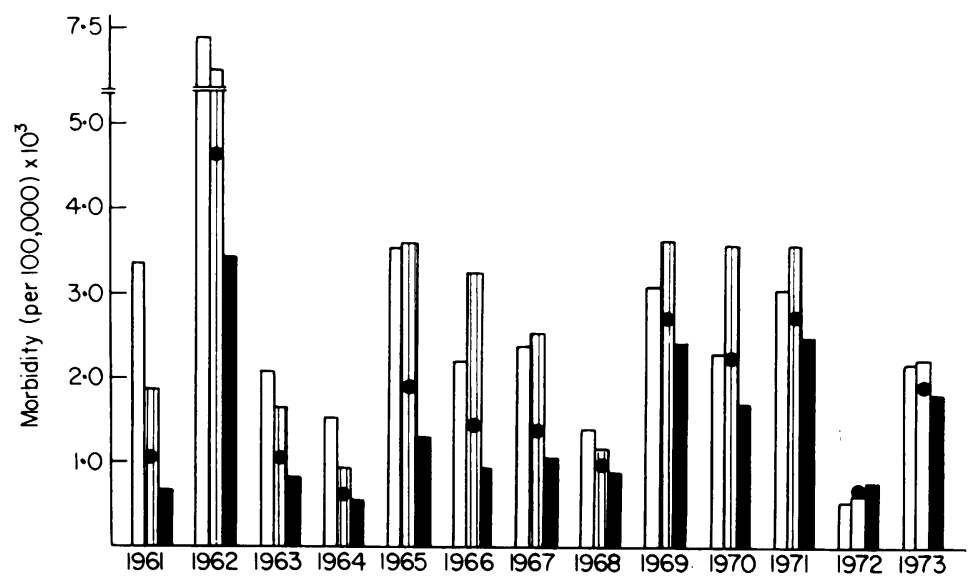

FIG. 2. Influenza morbidity by age groups in Rumania (1961-1973). $\square, 0-4$ years of age; [ind, 5-14 years of age; $\square, \geqslant 15$ years of age; 0 , all ages.

14 years being systematically observed later), and that school children may be the major source of introduction of influenza in family units, and therefore among high-risk segments of the population.

Exploring the relationship between influenza morbidity (per thousand of inhabitants), natality (per thousand of inhabitants) and mortality under 1 year of age (per thousand of live births), values of $<0.001$ have been obtained (Student's $t$-test). By evaluating the correlation between influenza morbidity and natality, as well as influenza morbidity and mortality under 1 year of age, the coefficients of product- moment correlation ( $r$ ) found were 0.2 and 0. 织. respectively. The linear regression analysis showed that both relationships were represented as straight lines with $\mathrm{p}_{0}=0.098$ and $\mathrm{p}_{0}=0.817$ respectively N $_{\text {N }}^{N}$
(Figs. 4 and 5 ).

There was no laboratory evidence to confirm the precise significance of influenza during pregnancyo Unfortunately our results are supported only byD epidemiological and statistical data. But many wor ${ }^{-}$ kers have shown experimentally that (1) the embryo ${ }^{-}$ can be damaged by normal metabolites (Coffey anc Jessop, 1959) and (2) in an attack of influenza there 


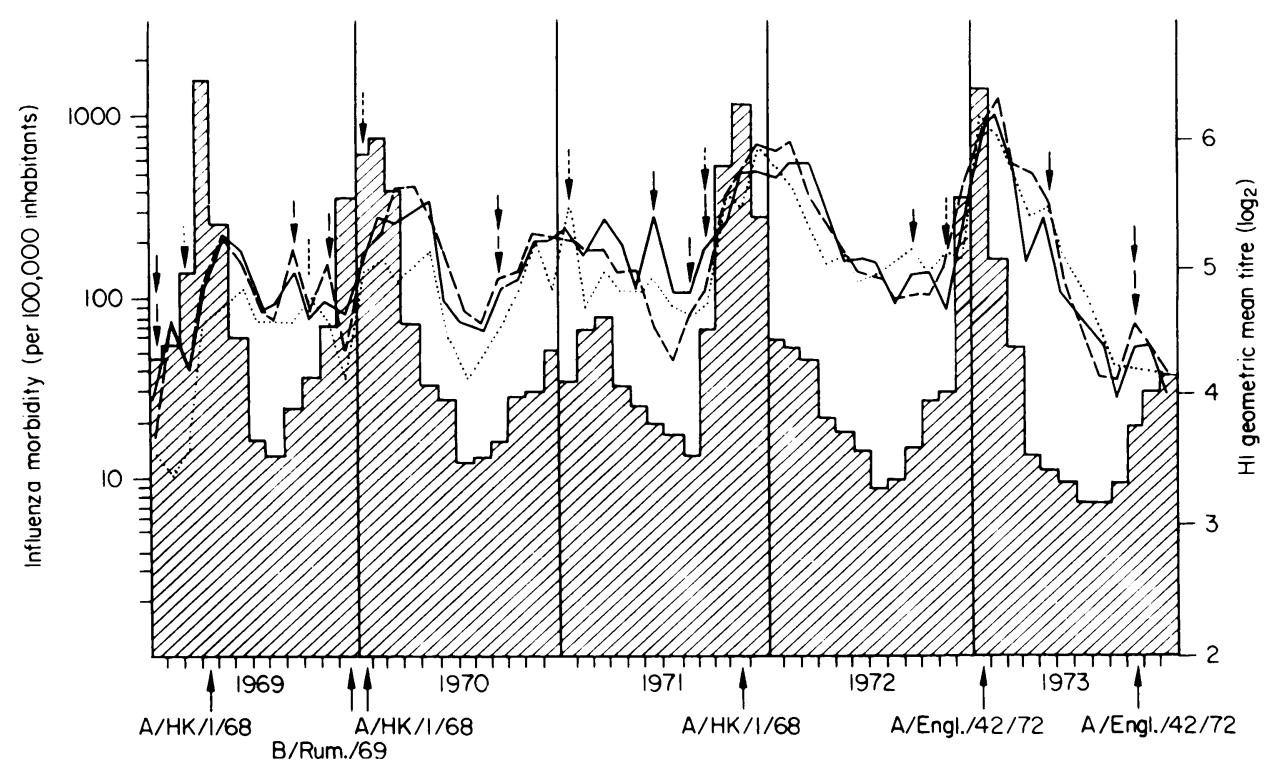

FIG. 3. Correlation between influenza morbidity and the serological survey of the population. $\downarrow \downarrow \downarrow$, Statistical significant increase of geometric means titres: $\mathscr{Z}$, influenza morbidity; --, $0-4$ years; ,$-- 5-14$ years $; \cdots \cdot 15-59$ years of age.

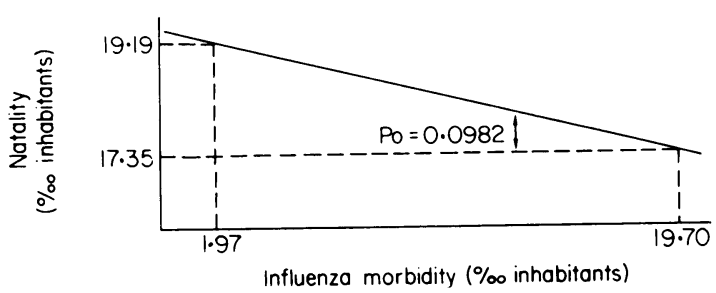

FIG. 4. Relationship between influenza morbidity and the natality.

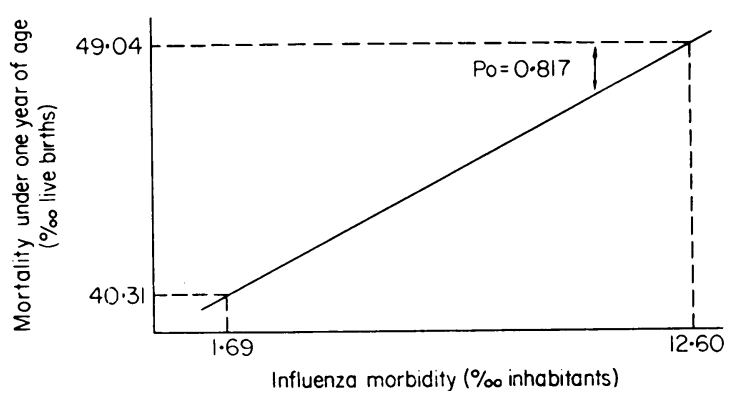

FIG. 5. Relationship between influenza morbidity and the mortality under 1 year of age.

can be no lack of metabolites arising from the damaged mucosa of the respiratory tract or even from the virus itself. Thus, metabolites which produced systemic reaction were reported by Bourne and Wedgwood (1959) and Skanse and Miörner (1959) in connection with the epidemic of Asian influenza.

It is possible to suppose that some of these substances could cross the placenta and interfere with the development of the embryo, and to provoke abortion, stillbirth or premature delivery.

In view of these data, it seems logical to utilize the available vaccine for the protection of infacts, school children and pregnant women. Their vaccineinduced protection can offer significant, although not total, protection to the whole population and prevent obstetrical accidents.

\section{References}

BARret-Connor, E. (1969) Infections and pregnancy: a review. Southern Medical Journal, 62, 275.

Bourne, G. \& Wedgwood, J. (1959) Heart disease and influenza. Lancet, i, 1226.

Cockburn, C.W. (1973) Influenza: the World problem. Medical Journal of Australia (Sp. Suppl.), $1,6$.

Coffey, P.V. \& Jessop, E.J.W. (1959) Maternal influenza and congenital deformities: a prospective study. Lancet, ii, 935.

Coffey, P.V. \& Jessop, E.J.W. (1963) Maternal influenza and congenital deformities. Lancet, i, 748.

DavenPort, M.F. (1973) Control of influenza. Medical Journal of Australia (Sp. Suppl.), 1, 33.

JORDAN, W.S., JR (1960) The mechanisms of Asian influenza. American Review of Respiratory Disease, 83, 29.

LANGmuiR, A.D. \& Housworth, J. (1969) A critical evaluation of influenza surveillance. Bulletin of the World Health Organization, 41, 393. 
Marcus, E.A., Liem, K.S. \& ANdre, F.E. (1974) Immunization schedules in influenza. Symposium on Immunity to Infections of the Respiratory System in Man and Animials, London, 22-25 April, 1974.

Mulder, J. \& Masurel, N. (1958) Asiatic influenza in the Netherlands. Influenza Symposium. Leiden, 17.
SKANSE, B. \& Miörner, G. (1959) Asian influenza with adrenocortical insufficiency. Lancet, i, 1121.

Wynne-Griffith, G., Adelstein, A.M., Lambert, P.M. \& WEATHERALL, J.A.C. (1972) Influenza and infant mortalitys. British Medical Journal, 3, 553. 